\title{
Sex-specific transcriptional regulation by the male and female doublesex proteins of Drosophila
}

\author{
Karen T. Coschigano and Pieter C. Wensink ${ }^{1}$ \\ Department of Biochemistry and The Rosenstiel Center, Brandeis University, Waltham Massachusetts 02254-9110 USA
}

\begin{abstract}
The somatic sexual phenotype of Drosophila is regulated by the sexual differentiation pathway. Male (DSX ${ }^{M}$ ) and female (DSX ${ }^{\mathrm{F}}$ ) proteins encoded by doublesex $(d s \mathrm{~s})$, a gene at the end of this pathway, bind to three sites within a 127-bp enhancer that directs sex- and tissue-specific transcription of Yolk protein genes. We describe mutagenesis of these binding sites and the resulting effects on $D S X^{M}$ and $D S X^{F}$ binding in vitro and on gene regulation in wild-type and $d s X$ mutant flies. The results demonstrate that $\mathrm{DSX}^{\mathrm{M}}$ represses and $\mathrm{DSX}^{\mathrm{F}}$ activates transcription from the two strongest binding sites. Thus, the pathway regulates sex-specific transcription through the male and female dsx proteins that act directly on the target gene, but with opposite effects.
\end{abstract}

[Key Words: Sexual differentiation; Yolk protein genes; fat body enhancer]

Received September 8, 1992; revised version accepted November 16, 1992.

The sexual differentiation pathway of Drosophila melanogaster is one of the best understood developmental regulatory pathways in eukaryotes. Since the discovery over 70 years ago of the initial signal determining sex in fruit flies, most of the major genes in the pathway as well as several target genes have been identified and cloned (for review, see Wolfner 1988; Baker 1989; Slee and Bownes 1990; Steinmann-Zwicky et al. 1990). Extensive genetic, molecular, and biochemical investigations have subsequently provided considerable insight into the mechanisms of regulation within the pathway.

The ratio of $\mathrm{X}$ chromosomes to autosomes is the initial signal setting the pathway as either male or female (Bridges 1921, 1925). Several genes involved in reading this chromosomal ratio have recently been identified and shown to regulate the transcription of a key binary switch gene, Sex-lethal $(S x)$, turning it on in females and off in males /Cline 1986, 1988; Parkhurst et al. 1990; Duffy and Gergen 1991; Erickson and Cline 1991; Keyes et al. 1992). Once set, the transcriptional state of $S x l$ is maintained by positive autoregulation of RNA processing (Bell et al. 1988, 1991; Salz et al. 1989). Sexual identity is then transmitted along the pathway by regulation of RNA processing (Boggs et al. 1987; Nagoshi et al. 1988; Bell et al. 1988; Burtis and Baker 1989; Sosnowski et al. 1989).

The link between the pathway and target genes encoding the sexual phenotype is poorly understood. Among known target genes, the Yolk protein $(Y p)$ genes cur-

${ }^{1}$ Corresponding author. rently are the best candidates for studying this link because their female-specific expression requires continuous action by the pathway and responds to changes within the pathway (Postlethwait et al. 1980; Bownes and Nöthiger 1981; Ota et al. 1981; Belote et al. 1985). The other known target genes are expressed in sex-specific tissues, such as ovaries, and require only a brief period of pathway activity, usually corresponding to the time of tissue differentiation and not to the time of target gene expression (Chapman and Wolfner 1988; Feng et al. 19911.

Previous experiments have indicated the molecules that may link the pathway to $Y p$ gene regulation. One of the final genes of the pathway, doublesex (dsx), is spliced differently in males and females to produce the DSX ${ }^{M}$ protein in males and the DSX $\mathrm{X}^{\mathrm{F}}$ protein in females (Burtis and Baker 1989). Genetic studies suggested that, either directly or indirectly, DSX ${ }^{M}$ represses female genes in males and DSX ${ }^{\mathrm{F}}$, in conjunction with another gene, intersex, represses male genes in females (Baker and Ridge 1980). This suggestion led to the prediction that DSX ${ }^{M}$ either directly or indirectly represses $Y p$ gene expression in males and that $\mathrm{DSX}^{\mathrm{F}}$ plays no role in $Y p$ regulation. Several observations give indirect support to this prediction but indicate that it may be an oversimplification. First, the restriction of $Y p$ transcription to females depends on $d s x$ products; deleting $d s x$ results in $Y p$ expression in both sexes, whereas synthesizing DSX ${ }^{\mathrm{M}}$ in females results in $Y p$ repression (Bownes and Nöthiger 1981; Ota et al. 1981). Second, both $\mathrm{DSX}^{\mathrm{M}}$ and $\mathrm{DSX}^{\mathrm{F}}$ bind in vitro to the same three sites in a $Y p$ regulatory element, the fat body enhancer (FBE; Burtis et al. 1991). 
This 127 -bp FBE can direct transcription from a heterologous promoter in the female-specific and fat body-specific manner characteristic of the Yp genes (Shepherd et al. 1985; Garabedian et al. 1986). These in vitro binding results suggest, but do not prove, that dsx proteins act directly on $Y p$ genes to direct the sex specificity of their transcription. The results, however, are inconsistent with the simplest interpretation of the genetic data because they suggest that $\mathrm{DSX}^{\mathrm{F}}$ may play a role in $Y p$ regulation.

In this paper we investigate the hypothesis that dsx proteins act directly on the FBE to regulate sex-specific transcription in vivo. To examine the regulatory role of dsx proteins at the FBE, we mutated each dsx-binding site by in vitro mutagenesis and then tested the effects on protein binding in vitro and on FBE-dependent regulation in wild-type and $d s x$ mutant flies. Our results demonstrate for the first time that in males, DSX ${ }^{M}$ acts directly to repress transcription. The results also demonstrate that, in females, DSX ${ }^{\mathrm{F}}$ activates transcription by acting at the same sites in the FBE. Finally, we show that in some situations the two proteins can compete to regulate FBE. Thus, both proteins connect the sexual differentiation pathway to a target gene by acting directly on the gene, one protein activating transcription in females and the other repressing transcription in males.

\section{Results}

Mutations in FBE sites independently reduce binding by $d s x$ proteins

Our previous in vitro binding studies demonstrated that Escherichia coli extracts containing overexpressed $\mathrm{DSX}^{\mathrm{M}}$ or $\mathrm{DSX}^{\mathrm{F}}$ proteins protect three sites within the FBE (Fig. 1; Burtis et al. 1991). Both proteins bind with highest affinity at the A site /shown for DSX ${ }^{\mathrm{M}}$ in Fig. 2; lane 2, wild-type FBE), 10-fold lower affinity at the $B$ site (lane 3), and a further 100-fold lower affinity at the $\mathrm{C}$ site (lane 5). For the experiments presented here, we mutated each site and examined the effect of the mutations on binding in vitro using a DNase I footprinting assay. Each mutation substituted a block of nucleotides within one binding site but made no changes in the spacing of other nucleotides within the FBE (Fig. 1).

The effects of the substitutions on $\mathrm{DSX}^{\mathrm{M}}$ binding are shown in Figure 2. Substitution $\mathrm{x}$ in the A site elimi-

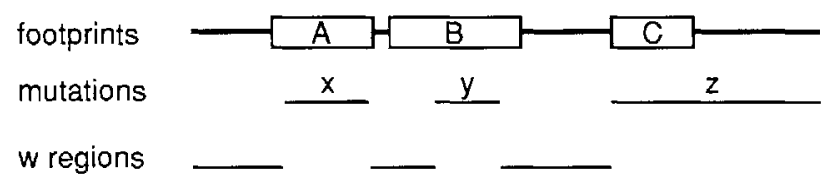

Figure 1. Scale diagram of footprints and mutations. FBE $(-322$ to -196$)$ is represented as a thick line oriented $5^{\prime}$ to $3^{\prime}$, left to right. The three dsx footprints (A, B, and C) are shown by open boxes, and the mutated regions $(x, y$, and $z)$ by thin lines. The remaining regions, collectively called $w$, are also shown as thin lines. nated binding at this highest affinity site (sub $x$, lanes 2-5). No binding was detected, even when protein concentration was increased 1000 -fold over that necessary to protect the unmodified A site. Binding at the B and C sites was unaffected, indicating that binding at these sites is independent of binding to A. Substitution $y$ within the $\mathrm{B}$ site greatly reduced $\mathrm{DSX}^{\mathrm{M}}$ binding at $\mathrm{B}$. No protection was seen at the protein concentration that produces a footprint at $B$ in the unmutated FBE (sub $y$, lane 3). As protein concentration was increased, however, very weak binding occurred at $B$, indicating that the substitution decreased binding by 100 -fold (sub y, lane 5). Binding at $A$ and $C$ was unaffected by sub y. Substitution $z$ eliminated detectable binding at the protein concentration normally used to detect footprint $\mathrm{C}$ (sub $z$, lane 5). Higher protein concentrations could not be tested because they lead to nonspecific binding by other proteins in the extract. Therefore, substitution $z$ decreases binding to $\mathrm{C}$ at least fivefold, the limit of detection in these experiments. As with the other two mutations, there was no effect on binding at unmutated sites.

These results indicate that mutating any single binding site reduces DSX ${ }^{M}$ binding at that site but has no effect on binding at the other two sites. To demonstrate that mutating two sites has no effect on binding at the remaining site, pairs of mutations were combined and tested. In each case, binding at the remaining site was unaffected (Fig. 3, sub yz, sub xz, sub xy). A final construct combining all three mutations showed only very weak binding at $B$ (sub $x y z)$.

Two other protein extracts were tested for binding to mutated FBEs. First, DSX ${ }^{\mathrm{F}}$ extract gave footprinting results indistinguishable from those with DSX ${ }^{M}$ extract and all mutations in all combinations (data not shown). Second, control extract without dsx protein was incubated with sub xyz. No footprints were detected, indicating that the weak protection of $B$ is attributable to $d s x$ protein and not another protein (data not shown).

In summary, the substitutions greatly reduce DSX ${ }^{M}$ and DSX ${ }^{\mathrm{F}}$ binding at each mutated site. Also, each dsx protein appears to bind independently at each site.

\section{Male-specific repression from the $\mathrm{x}$ and $\mathrm{y}$ regions}

To test the proposed negative regulatory role of dsx-binding sites in males, each mutated FBE was placed immediately upstream of a Drosophila heat shock promoter fused to the $E$. coli $\beta$-galactosidase structural gene $(-44$ $h s p / l a c$ reporter construct) and integrated into the fly genome by P-element-mediated transformation. The $x$, $y$, and $z$ mutations greatly diminish DSX ${ }^{\mathrm{M}}$ protein binding in vitro, and therefore, were expected to interfere with repression by $\mathrm{DSX}^{\mathrm{M}}$ in vivo, resulting in expression of $\beta$-galactosidase in male fat body cells.

Figure 4 shows the activity of $\beta$-galactosidase in transformed flies as revealed by histochemical staining. As expected, the vector alone gave no fat body staining whereas adding FBE produced strong fat body staining in females but not in males (constructs -44 and FBE). In support of the negative regulatory role for dsx-binding 
FBE

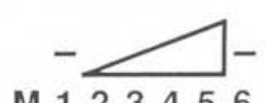

M123456

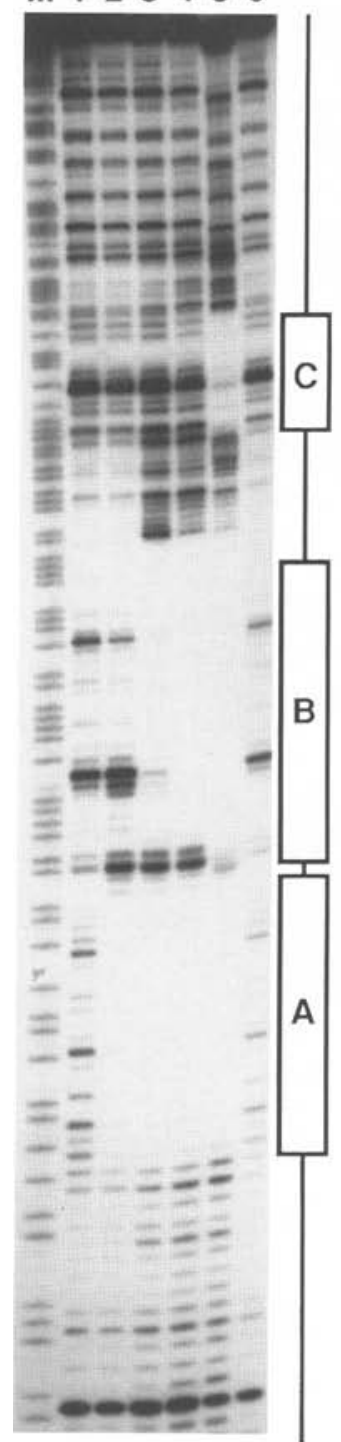

sub $x$

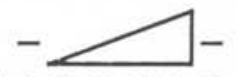

M123456

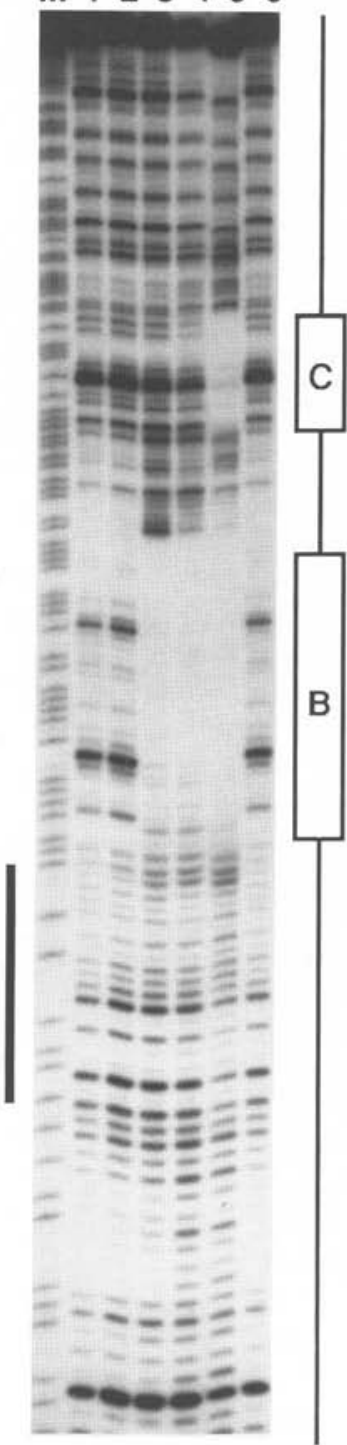

sub y

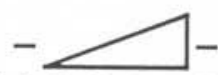

M123456

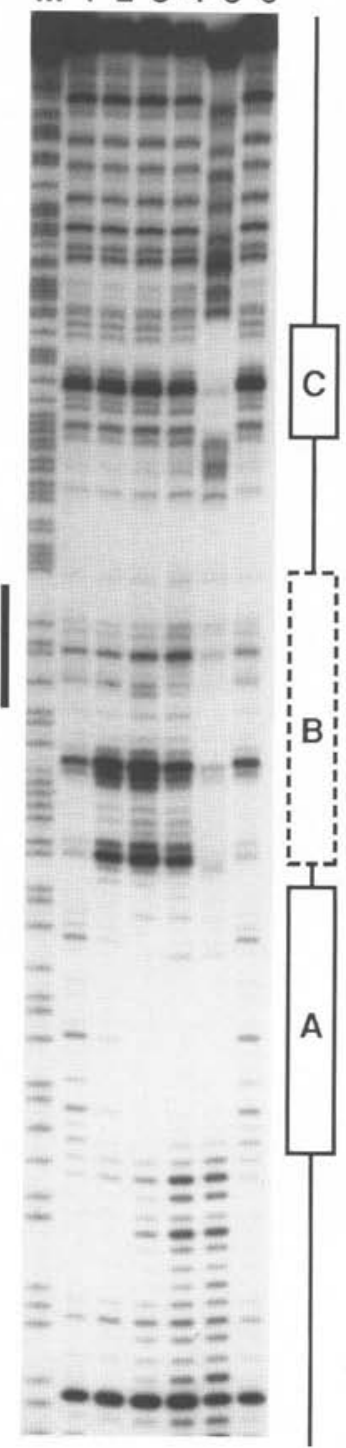

sub z
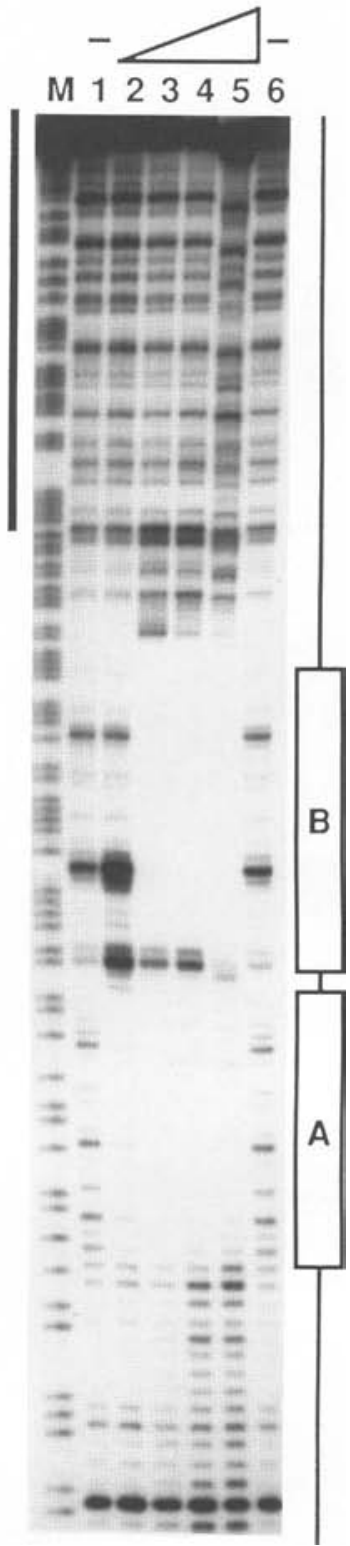

Figure 2. DSX ${ }^{M}$ binding to unmodified and modified FBE. Extract containing DSX ${ }^{\mathrm{M}}$ was diluted 1000-fold (lane 2), 100-fold (lane 3), 10-fold (lane 4), or not at all (lane 5), incubated with the indicated radiolabeled FBE DNA, and analyzed by DNase I footprinting. No extract was added to reactions for lanes 1 and 6 . The $M$ lanes are $A+G$ chemical degradation sequencing ladders of each corresponding DNA fragment (Maxam and Gilbert 1980). The mutated sequence in each substitution is indicated by the vertical line at left, and the detected footprints are indicated by boxes to the right. The dotted box indicates a weak footprint at B.

sites in males, mutation of the strongest binding site, A, resulted in strong staining in the fat body cells of males, staining that ranged from half to nearly the same intensity as observed in females (sub $x$ ). Mutation of the 10fold weaker binding site, $B$, resulted in moderate staining in fat body cells of males (sub $y$ ), whereas mutation of the weakest site, C, gave no staining in males (sub $z$ ). Mutation of both A and B gave nearly the same staining as in females (sub xy). Thus, the two strongest dsx-binding sites identified in vitro are each necessary for full male-specific repression in vivo, providing the first evidence that $D_{S X^{M}}$ interacts directly with FBE to regulate sex-specific transcription in the fly.

The repression in males caused by each of the strong dsx-binding sites can be quantitated by spectrophotometric assays of $\beta$-galactosidase activity in whole-fly extracts. Results with this assay correlate well with the steady-state levels of $h s p / \beta$-galactosidase mRNA and thus appear to be a good estimate of transcription from the reporter (Simon and Lis 1987). Restoring wild-type 
sub yz

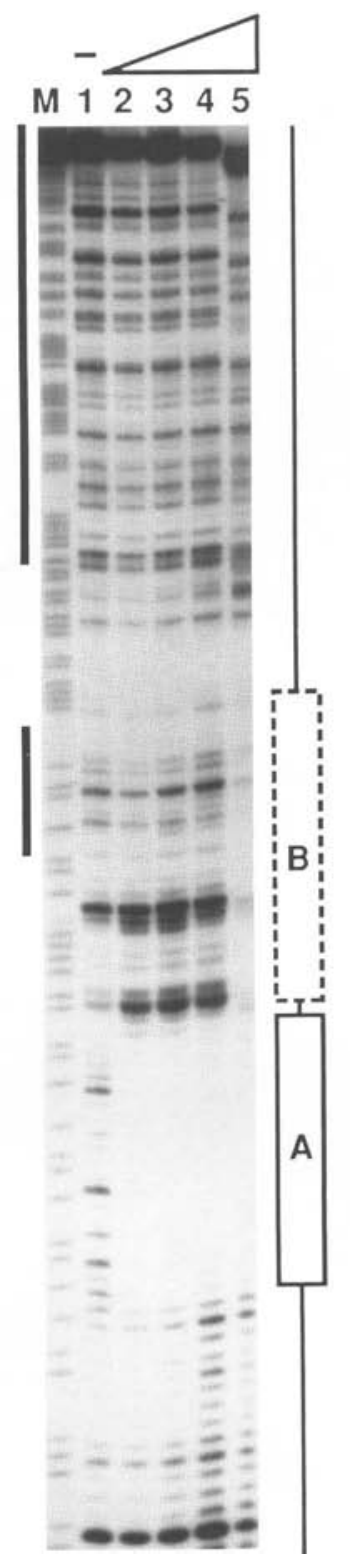

sub $x z$
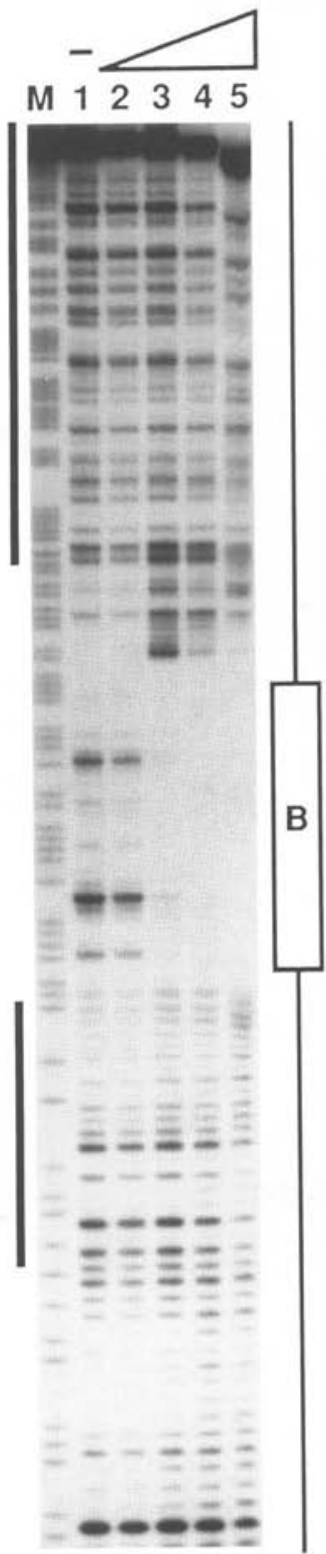

sub xy
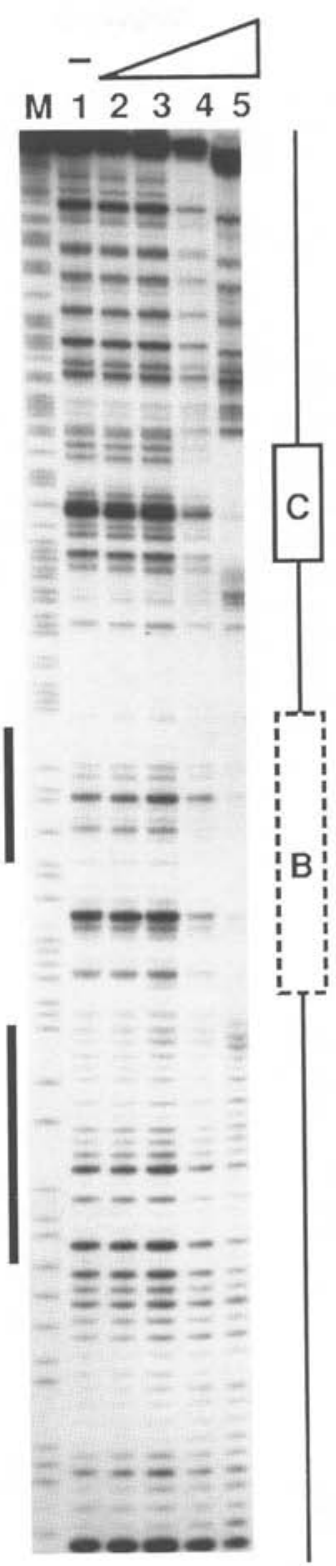

sub xyz

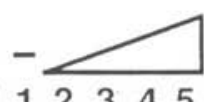

M 1223345

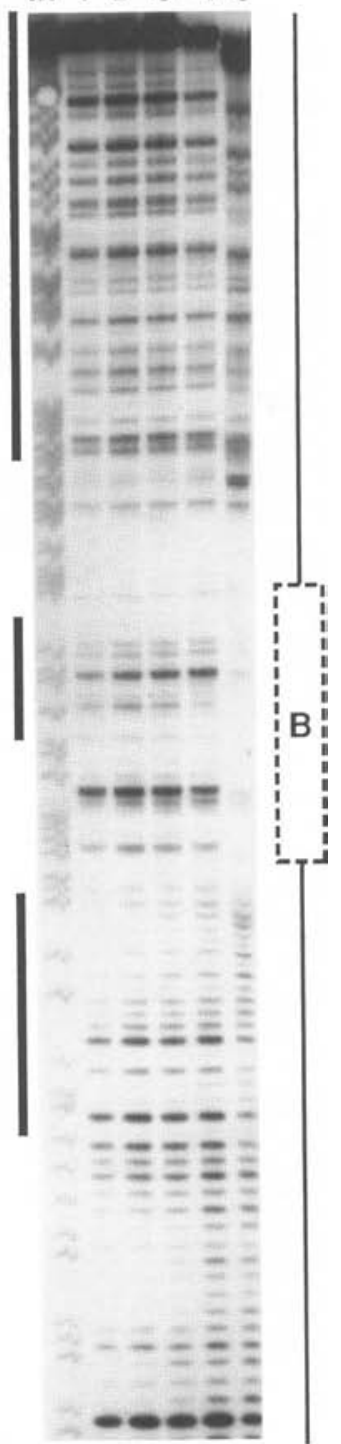

Figure 3. $\mathrm{DSX}^{\mathrm{M}}$ binding to FBE with double and triple substitutions. See the legend for Fig. 2 for details.

region $\mathrm{x}$ resulted in $\sim 80 \%$ repression of the activity from the xy double mutant (Fig. 5, males, line 6 vs. 8). Restoring region $\mathrm{y}$ to the same double mutant also resulted in $\sim 80 \%$ repression of the activity (Fig. 5, males, line 6 vs. 7). The nearly equal repression strength of each region does not reflect the 10 -fold difference in affinity for $\mathrm{DSX}^{\mathrm{M}}$ observed in the in vitro binding experiments, perhaps indicating the presence of a saturating concentration of $\mathrm{DSX}^{\mathrm{M}}$ in vivo. Together, the two sites repress at least $98 \%$ of the activity, confirming the impression from staining that the two sites not only can repress independently, but also can repress together in the same enhancer (Fig. 5, males, line 6 vs. 2 minus the background shown in line 1 .
Four regions of FBE activate transcription in female fat bodies

Although the $\mathrm{x}, \mathrm{y}$, and $\mathrm{z}$ mutations were designed to interfere with the proposed negative sex-specific regulation by $\mathrm{DSX}^{\mathrm{M}}$ at the $\mathrm{A}, \mathrm{B}$, and $\mathrm{C}$ sites, they may also interfere with activation by other proteins that bind to the same or overlapping sites. To determine whether this is the case, we examined the effects of the mutations on expression in females, because expression in females should reveal activators without interference from DSX $^{\mathrm{M}}$ repression.

The triple mutation, sub xyz, substantially decreased staining in female fat bodies (Fig. 4, sub xyz vs. FBE). 


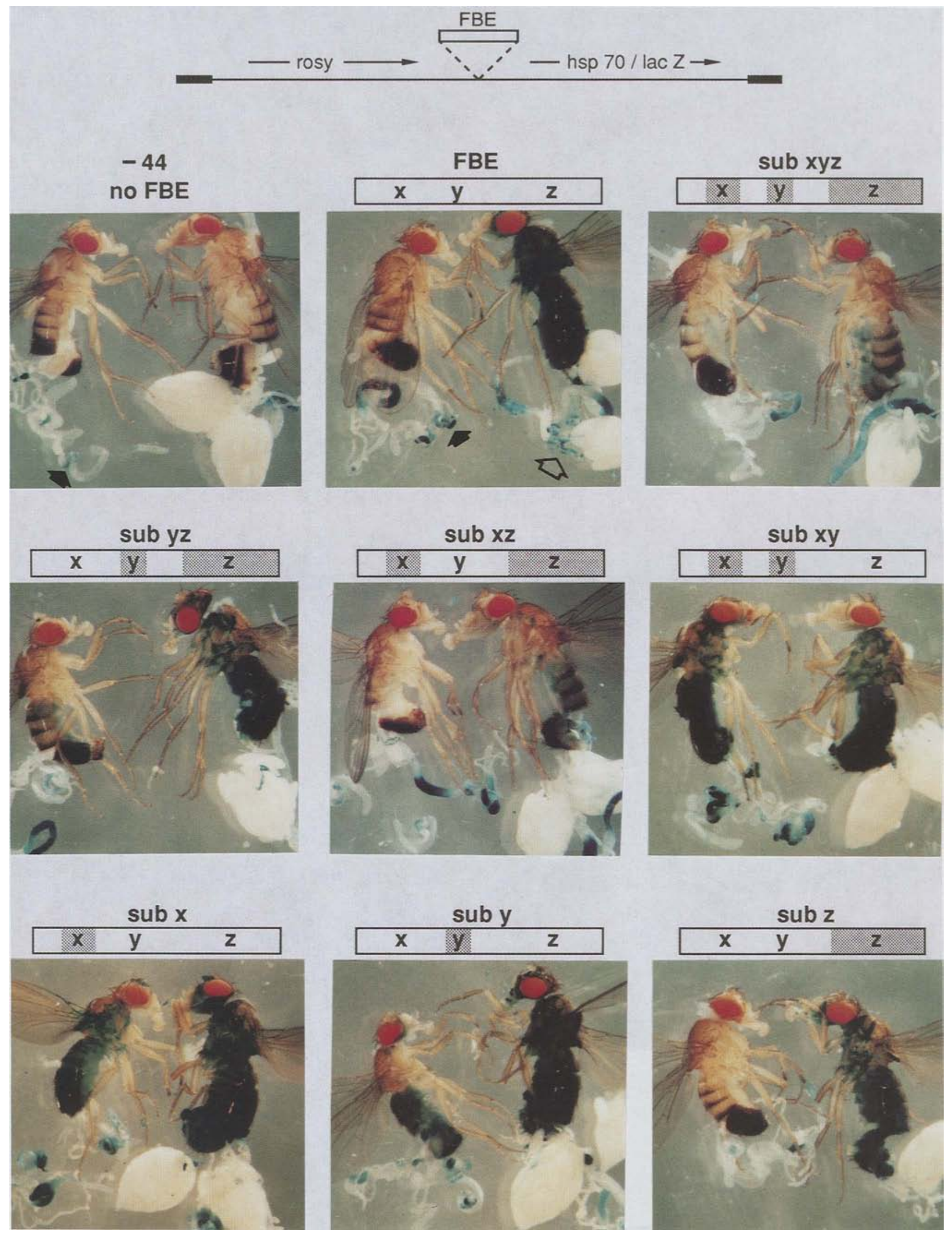

Figure 4. (See facing page for legend.) 
Females

\begin{tabular}{lr}
\multicolumn{2}{r}{ censtruct } \\
1) & -44 \\
2) & FBE \\
3) & sub $x y z$ \\
4) & sub $y z$ \\
5) & sub $x z$ \\
6) & subxy \\
7) & sub $x$ \\
8) & sub $y$ \\
9) & sub $z$
\end{tabular}
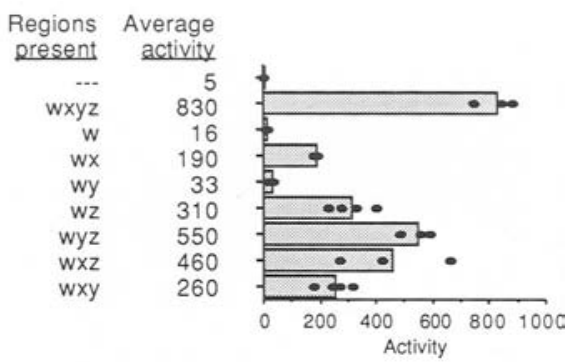

Males

$$
\begin{array}{r}
w x y z \\
w \\
w x \\
w y \\
w z \\
w y z \\
w x z \\
w x y
\end{array}
$$

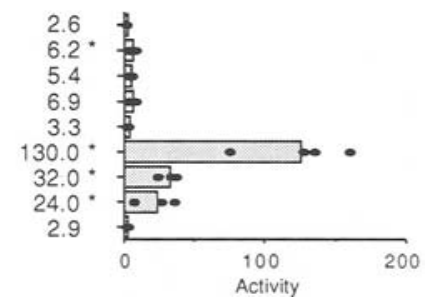

Figure 5. $\beta$-Galactosidase activity in transformed flies. The average activity $\left[\left(\Delta A_{574} / \mathrm{min}\right.\right.$ per $\left.\left.\mathrm{fly}\right] \times 10^{4}\right]$ for each construct is given in the final column and shown to the right as a shaded horizontal bar. The average of assays for each line is represented by a dot. Standard deviations for each line ranged from $3 \%$ to $34 \%$. Differences between lines probably reflect chromosomal position effects. Asterisks $\left({ }^{\star}\right)$ indicate lines likely to have increased background $(-3$ units $)$ because of strong seminal vesicle activity observed in staining assays.

This indicates that at least one of the mutations interferes with an activator necessary for high levels of expression. Because weak fat body staining was observed in the triple mutation, it also suggests weak activation from the remaining DNA, w region (Fig. 1). This weak activation could be a w-specific activator or a strong $x, y$, or $z$ activator that binds to the portion of a binding site that remains after mutation. In either case, weak activity is associated with $\mathrm{w}$. The spectrophotometric assays indicate that $\mathrm{w}$ directs $<1 \%$ of the total FBE activity in females (Fig. 5, females, lines 2 and 3 minus line 1). The activity measured for $\mathrm{w}$ may be of little statistical significance and is best interpreted as an upper limit.

To determine the region or regions of the FBE that are required for strong expression in females, the three double mutations were tested, each restoring one potential activator region to the weakly activating $w$ region. Restoring the wild-type $x$ region greatly increased staining in fat body cells throughout the female, suggesting the presence of a strong activator binding site in $\mathrm{x}$ (Fig. 4, sub yz). Quantitatively, this corresponds to more than a 10- fold increase in activity (Fig. 5, females, line 4 vs. 3). Restoring only the wild-type y region had a much weaker effect, a slight increase in abdominal fat body staining and an approximately twofold increase in activity, suggesting a weak activator binding site in $\mathrm{y}$ (Fig. 4, sub xz vs. sub xyz; Fig. 5 , females, line 5 vs. 3). Restoring only wild-type $z$ region had the largest effect, nearly 30 -fold (Fig. 4, sub xy vs. sub xyz; Fig. 5, females, line 6 vs. 3). In summary, the simplest interpretation of these results is that in females all four regions activate transcription, with $\mathrm{x}$ and $\mathrm{z}$ having the strongest effects.

\section{The $w$ and $z$ regions of FBE can activate transcription in males}

The $w$ and $z$ regions, two of the four regions that activate transcription in females, also activate transcription in males. The other two activator regions, $x$ and $y$, either overlap or coincide with the identified male-specific repressor regions and therefore could not be tested for activation. The xyz triple mutation resulted in very weak staining in male fat bodies, staining similar to that observed in females with the same FBE mutation (Fig. 4, sub xyz). This indicates that $w$ activates tissue-specific transcription weakly in both sexes. Adding back the wild-type $z$ region resulted in strong staining of male fat bodies, indicating that $z$ is a strong tissue-specific activator in both sexes (Fig. 4, sub xy). Quantitation of $\beta$-galactosidase activities indicates that $w$ and $z$ direct twoto fourfold less activity in males than in females despite the similar number and size of fat body cells in the two sexes (Fig. 5, sub xyz and sub xy; Johnson and Butterworth 1985). Therefore, $w$ and $z$ direct transcription in male fat bodies, but their activities are either somewhat weaker or partially repressed in males.

\section{$D S X^{M}$ acts through the $\mathrm{x}$ and $\mathrm{y}$ regions to repress transcription}

We have shown that the $\mathrm{x}$ and $\mathrm{y}$ mutations dramatically reduce $D_{S X}{ }^{M}$ binding to the $A$ and $B$ sites in vitro and that these same mutations derepress transcription in males. These results imply that in the organism, DSX acts directly at those sites to repress transcription. To examine this possibility, we investigated the expression of several $\mathrm{FBE} /$ reporter constructs in flies with different $d s x$ alleles. One allele, $d s x^{M+R 15}$, is a deletion of the entire $d s x$ locus (Baker et al. 1991). The other allele, $(3 \mathrm{R}) d s \mathrm{x}^{D+R 3}$, is an inversion with a breakpoint in the $d s x$ gene (Duncan and Kaufman 1975). These mutant $d s x$ alleles are recessive such that chromsomally male and

Figure 4. $\beta$-Galactosidase staining patterns in transformed flies. The reporter construct is drawn at the top (not to scale) with thick lines at either end indicating P-element DNA. The arrows indicate the direction of transcription. The broken lines mark the location of the insertion of FBE. Male (left) and female (right) adults transformed with the reporter containing the indicated FBE are shown dissected and stained. Fat body cells are located in the head, thorax, and abdomen. Background staining from the fly reporter construct occurs in the intestines, the testes $(-44$, solid arrow), the seminal vesicles (FBE, solid arrow), and the female Malpighian tubules (FBE, open arrow). 


\section{Coschigano and Wensink}
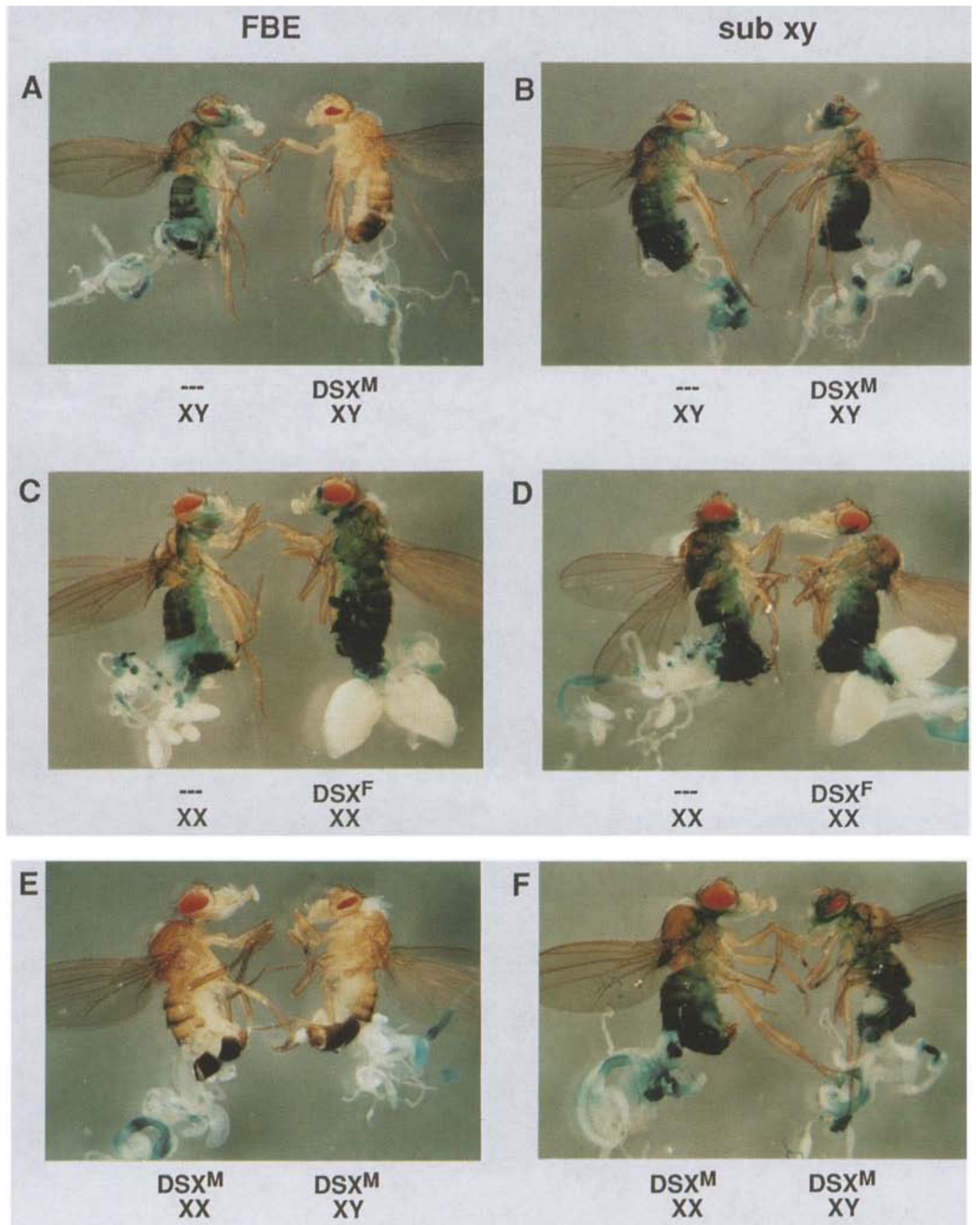

F

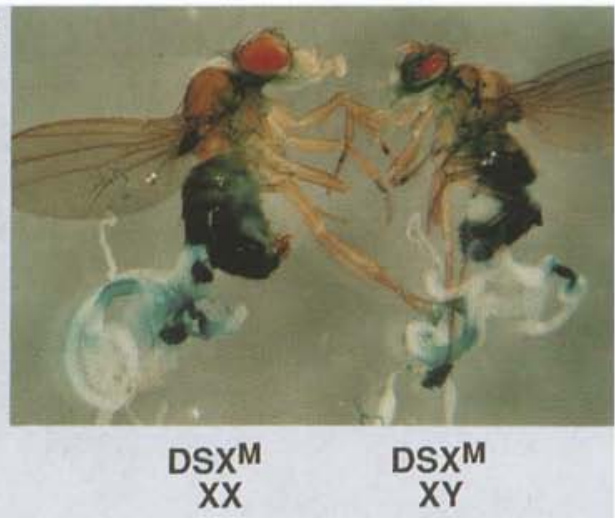

G

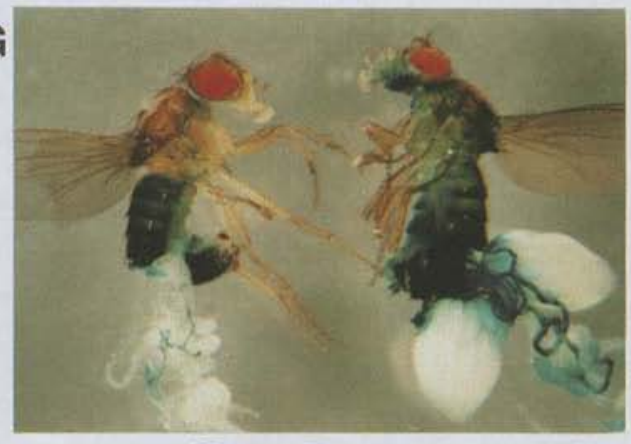

H

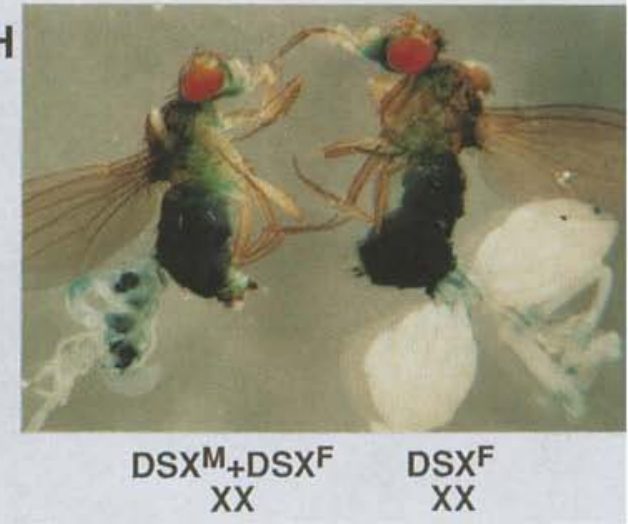

Figure 6. (See facing page for legend.) 
female flies with a single copy of the wild-type $d s x$ gene $\left(d s x^{M+R 15} / d s x^{+}\right)$have the normal male and female phenotype, whereas chromosomally male or female flies with mutations in both copies of the gene $\left\langle d s x^{M+R 15}\right\rangle$ $d s x^{D+R 3}$ ) have the intersexual phenotype. Although a shortened transcript from $d s x^{D+R 3}$ is detected in these intersexual flies (R. Nagoshi, pers. comm.), the intersexual phenotype as judged by abdominal pigmentation, genital structure, and bristle patterns is extreme, indicating that $\mathrm{dsx}$ protein activity is either eliminated or at very low levels.

FBE-directed transcription occurs in fat body cells of flies lacking DSX ${ }^{\mathrm{M}}$, but is repressed 15 - to 20 -fold when $D_{S X}{ }^{M}$ is present, indicating that DSX ${ }^{M}$ is required for repression (Fig. 6A; Fig. 7, line 6 vs. 5 ). This $\mathrm{DSX}^{\mathrm{M}}$-dependent repression depends substantially on the $x$ and $y$ regions. When $\mathrm{x}$ and $\mathrm{y}$ are mutated, the addition of $\mathrm{DSX}^{\mathrm{M}}$ resulted in less than a twofold repression of FBE-directed activity (Fig. 6B; Fig. 7, line 10 vs. 9). We conclude that in vivo, $\mathrm{DS} \mathrm{X}^{\mathrm{M}}$ binds directly to $\mathrm{x}$ and $\mathrm{y}$ to repress almost all of the tissue-specific activation from the FBE.

\section{DSX $X^{F}$ acts through the $\mathrm{x}$ and $\mathrm{y}$ regions to activate transcription}

In contrast to the results just described demonstrating repression by $D S X^{M}$, we find that $D_{S X}{ }^{F}$ activates the female-specific transcription directed by FBE. In the $d s x$ double mutant described above, little or no DSX $\mathrm{X}^{\mathrm{F}}$ should be present in females. In these intersexual females, unmutated FBE directs moderate expression in fat body cells (Fig. 6C, left). This expression level is nearly the same as in $d s x$ double mutant males, which similarly lack DSX ${ }^{\mathrm{M}}$, suggesting that this is the level of FBE-directed transcription when there is no sex regulation (Fig. 7 , line 7 vs. line 6). Heterozygous females with a single gene for DSX ${ }^{\mathrm{F}}$ had more than a fourfold increase in activity, demonstrating activation by $\mathrm{DSX}^{\mathrm{F}}$ (Fig. 6C, right; Fig. 7 , line 7 vs. 8). The total FBE activity in heterozygotes was comparable to the activity observed in flies with two wild-type copies of $d s x$, suggesting that a single gene produces saturating quantities of $\mathrm{DSX}^{\mathrm{F}}$ (Fig. 5, line 2).

DSX $^{\mathrm{F}}$ activation from FBE depends mainly on the $\mathrm{x}$ and $\mathrm{y}$ regions. In the $d s x$ double mutant, sub xy gave moderate activity throughout the fat bodies (Fig. 6D, left). Adding a single wild-type $d s x$ gene to females with the same $x y$ substitution resulted in less than a 1.3 -fold increase in activity for all three lines assayed, an increase substantially lower than the fourfold change caused by $\mathrm{DSX}^{\mathrm{F}}$ with the unmutated FBE (Fig. 6, C vs. D, left; Fig. 7 , line 11 vs. 12$)$. We conclude that DSX ${ }^{F}$ activates FBEdirected transcription in females, primarily through the $\mathrm{x}$ and $\mathrm{y}$ regions.
$D S X^{M}$ and $D S X^{F}$ have competing effects on FBEdirected transcription

The results described above indicate that $\mathrm{DSX}^{\mathrm{F}}$ and DSX $^{M}$ have independent and opposite effects on transcription when they bind to the $x$ and $y$ regions of FBE. This leads to the prediction that if both proteins were present in the same fly, they would have opposite and competing effects on transcription directed by FBE. We tested this hypothesis using a dominant allele, $d s x^{T}$, that constitutively expresses DSX ${ }^{\mathrm{M}}$.

A chromosomally female $d s x^{+} / d s x^{T}$ heterozygote has an intersexual phenotype because it produces both DSX ${ }^{F}$ and DSX ${ }^{M}$ proteins (Nagoshi and Baker 1990). Such flies have $>10$-fold lower expression from the FBE/hsp/lac gene construct than do $d s x^{+} / d s x^{+}$homozygous females that produce only $\mathrm{DSX} \mathrm{X}^{\mathrm{F}}$, indicating that the two proteins have competing effects on transcription (Fig. 6G, right vs. left; Fig. 8 , line 7 vs. 8). As expected, most of this competition depends on the $\mathbf{x}$ and $\mathbf{y}$ regions because sub $x y$ reduced to less than twofold the repression that re-

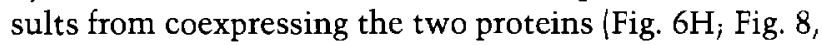
lines 11 and 12). An indication that this competition may occur at the $x$ and $y$ sites and not through forming nonfunctional DSX ${ }^{\mathrm{F}}$-DSX ${ }^{\mathrm{M}}$ complexes in solution (Burtis and Baker 1989; Steinmann-Zwicky et al. 1990) is the observation that DSX ${ }^{M}$ can act at FBE in females. DSX ${ }^{M}$ strongly represses transcription in chromosomal females that have little or no DSX ${ }^{\mathrm{F}}$ (Fig. 6E, left vs. right) and this DSX $^{\mathrm{M}}$-directed repression requires the presence of the $\mathrm{X}$ and y regions (Fig. 6F; Fig. 8, line 10 vs. 6 ).

\section{Discussion \\ dsx proteins act directly and oppositely on a target gene to regulate the sex specificity of transcription}

Evidence provided in this paper demonstrates that two proteins encoded by the $d s x$ gene, DSX ${ }^{\mathrm{F}}$ and $\mathrm{DSX}^{\mathrm{M}}$, are direct links between the sexual differentiation pathway and the sex-specific transcriptional regulation of a pair of target genes, $Y p 1$ and $Y p 2$. We found that mutating two sites within the Yp1-2 enhancer, FBE, substantially reduces binding by both dsx proteins in vitro and also eliminates almost all of the sex-specific regulation by FBE in vivo. Furthermore, using mutants of the $d s \mathrm{x}$ gene, we demonstrated that both proteins require these two FBE sites to regulate the sex specificity of transcription in vivo. Thus, the only way these two proteins might not be direct links would be if they regulate other regulatory proteins that happen to bind the same sites in FBE as do the dsx proteins. We believe that this is highly unlikely and therefore conclude that the experiments have identified the protein molecules and the DNA-binding sites

Figure 6. $\beta$-Galactosidase staining patterns in $d s x$ mutants. The stained adults contain the FBE/hsp/lac construct indicated above each column. The dsx protein (DSX ${ }^{\mathrm{M}}$ or DSX) expressed in the fly and the chromosomal sex (XX or XY) are indicated below each photograph. The broken line indicates that no dsx protein is expected. 
that directly connect the pathway to target gene regulation.

Although these experiments have demonstrated the role of dsx proteins in linking the pathway to target gene regulation, it is possible that another protein of the pathway acts together with the dsx proteins to accomplish this regulation. The most likely candidate for this is the intersex gene protein, which in females is known to act in conjunction with $\mathrm{DSX}^{\mathrm{F}}$ to repress male-specific genes (Baker and Ridge 1980).

Both dsx proteins bind to the same sites in FBE but have opposite effects on transcription. DSX ${ }^{M}$ represses and $\mathrm{DSX}^{\mathrm{F}}$ activates transcription. Our finding that $\mathrm{DSX}^{\mathrm{M}}$ is a strong repressor of transcription is entirely consistent with previous genetic results, which demonstrated that, in the absence of dsx proteins, Yps were expressed, whereas in the presence of DSX ${ }^{M}$, Yp gene expression was repressed (Bownes and Nöthiger 1981; Ota et al. 1981). In contrast to our findings for $\mathrm{DSX}^{\mathrm{M}}$, the observation that $\mathrm{DSX}^{\mathrm{F}}$ activates FBE-directed transcription in females is inconsistent with the simplest interpretation of previous genetic results, namely, that $D_{S X}{ }^{F}$ is a repressor of male-specific genes (Baker and Ridge 1980). There have been some indications that $\mathrm{DSX}^{\mathrm{F}}$ has a positive regulatory role; for example, it has recently been found that both dsx proteins act positively to stimulate sex-specific neuroblast development (Taylor and Truman 1992). In all cases suggesting positive regulation by dsx proteins, however, the phenotypes examined were morphological and may have resulted from the action of many genes, including regulators downstream of $d s x$. In contrast, our results allow a more direct interpretation, giving strong evidence that both male repression and female activation of $\mathrm{Yp}$ transcription result from direct action by the dsx proteins on particular target genes.

\section{Activation of transcription in fat bodies}

The experiments described in this paper demonstrate that $\mathrm{DSX}^{\mathrm{F}}$ is not the only transcriptional activator oper-

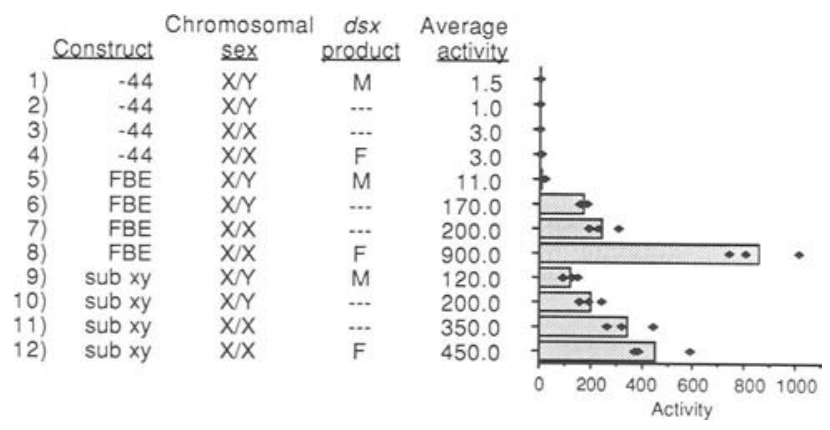

Figure 7. $\beta$-Galactosidase activity in flies lacking dsx proteins. The dsx protein present in the fly is indicated by $M\left(D S X^{M}\right.$; haploid $d s x$ ), $\mathrm{F}$ (DSX ; haploid $d s \mathrm{~F}$ ), and a broken line (no dsx protein expected in the $d s x$ double null) (for details, see Fig. 5). Standard deviations for each line ranged from $7 \%$ to $89 \%$. The absolute level of activity in these flies cannot be compared directly with data from Fig. 5 because genetic backgrounds differ.

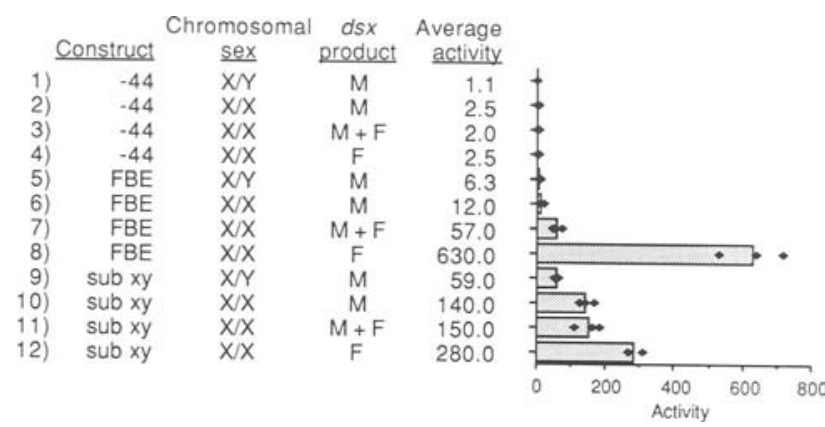

Figure 8. $\beta$-Galactosidase activity in flies expressing both dsx proteins. The $d s x$ protein present in the fly is indicated $M$ $\left(\mathrm{DSX}^{\mathrm{M}}\right)$ or $\mathrm{F}\left(\mathrm{DSX} \mathrm{F}^{\mathrm{F}}\right.$ ) (for details, see Figs. 5 and 7 ). Standard deviations for each line ranged from $0 \%$ to $76 \%$. Female flies in lines 4,8 , and 12 have two wild-type $d s x$ alleles and therefore are likely to produce DSX ${ }^{F}$ at twice the level of the DSX ${ }^{M}$ in males and pseudomales (see Materials and methods).

ating in FBE. DSX ${ }^{F}$-dependent activation is only fourfold (Fig. 7, lines 7 and 8), whereas FBE-mediated activation in females is at least several hundred-fold (Fig. 7, lines 4 and 8 ). Furthermore, the weakest DSX ${ }^{\mathrm{F}}$-binding site in $\mathrm{FBE}, z$, gives the strongest activation in females, suggesting that other proteins act in that region to determine the strength of activation. Finally, activation can occur in males where no DSX ${ }^{F}$ is found.

Activation of transcription in fat bodies appears to occur through two tissue nonspecific regions that require $\mathrm{DSX}^{\mathrm{F}}$ and two tissue-specific regions that do not require $D_{S X^{F}}$. Activation by $\mathrm{x}$ and $\mathrm{y}$ appears totally dependent on $\mathrm{DSX}^{\mathrm{F}}$ because they do not activate transcription in flies lacking dsx protein (Fig. 7, line 6 vs. 10 and 7 vs. 11) but do activate in the presence of DSX ${ }^{\mathrm{F}}$ (Fig. 7, line 8 vs. 121. In contrast, activation by $\mathrm{w}$ and $\mathrm{z}$ is largely sex independent and occurs in the absence of dsx protein (Figs. 4 and 5, sub xyz and sub xy; Fig. 7, line 3 vs. 11 . Although further study may show that $\mathrm{x}$ and $\mathrm{y}$ contribute to DSX $\mathrm{F}^{\mathrm{F}}$-independent activation, it seems most likely that fat body specificity of FBE activation is directed by the $w$ and $z$ regions.

Studies of a different FBE, the adult enhancer (AAE) of the Alcohol dehydrogenase (Adh) gene, suggest three proteins that could be involved in fat body-specific regulation by FBE. Two of the proteins, C/EBP and BBF2, are activators of $A d h$ and the third, AEF1, is a repressor (Abel et al. 1992; Falb and Maniatis 1992). All three of these proteins bind to FBE in vitro, suggesting that $\mathrm{C} / \mathrm{EBP}$ and BBF2 may be responsible for the tissue-specific activation by FBE (Abel et al. 1992; Falb and Maniatis 1992; W.C. An and P.C. Wensink, unpubl.). The only binding site detected for BBF2 is in $z$. Because our results demonstrate that $z$ is a strong, fat body-specific activator, $\mathrm{BBF} 2$ could be a major tissue-specific activator of FBE. It seems that the other activator protein, C/EBP, is not likely to play such a role because it does not appear to bind in vitro to either of the tissue-specific activation regions of FBE, $w$ or $z$ but, instead, binds to the sexspecific $\mathrm{x}$ region. 


\section{Sex-specific regulation of tissue-specific activation}

The simplest interpretation of our results is that dsx proteins bound at $\mathrm{x}$ and $\mathrm{y}$ regulate sex-specific transcription by altering the activity of sex-independent, but tissuespecific, activators that bind to $\mathrm{w}$ and $\mathrm{z}$. Two ways in which the dsx proteins could influence activation are through changing the affinity of activators for $w$ and $z$ or through changing the activity of the activators once they are bound. Figure 9 diagrams this interpretation for each of the cases examined in this paper: the female; the male; and the two different intersexual flies, one with neither dsx protein and the other with both proteins. Because our footprinting experiments show that the two $\mathrm{dsx}$ proteins are likely to bind $\mathrm{x}$ and $\mathrm{y}$ identically, we presume that their identical amino-terminal regions bind DNA, a presumption supported by the recent demonstration that the amino-terminal regions of $\mathrm{DSX}^{\mathrm{F}}$ and DSX $^{\mathrm{M}}$ share a DNA-binding domain (S.E. Erdman and K.C. Burtis, pers. comm.l. We presume further that their different carboxy-terminal regions are responsible for the fourfold activation by DSX ${ }^{\mathrm{F}}$ and the 90 -fold repression by $\mathrm{DSX}^{\mathrm{M}}$. Finally, because we have shown that dsx proteins

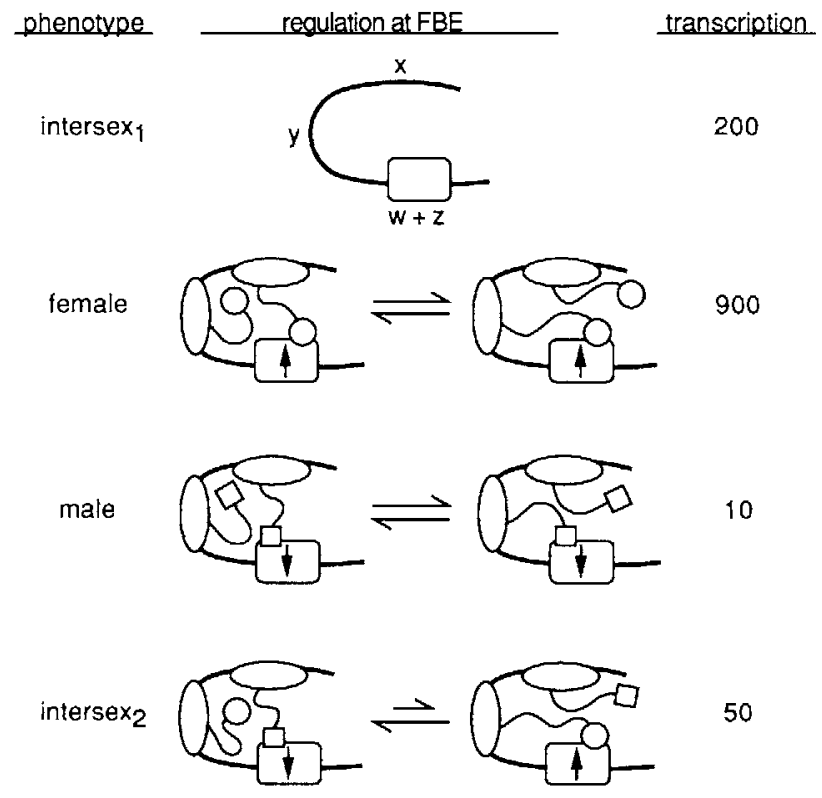

Figure 9. Activation and repression at FBE. The first column lists the sexual phenotype of flies. The two intersexual phenotypes are designated interse $x_{1}$ (no dsx protein) and interse $x_{2}$ (both dsx proteins). The second column diagrams the proposed interactions. FBE DNA (thick line) is bound by activator proteins (rounded rectangle). Arrows within the activator protein represent dsx protein-induced activation (upward) and repression (downward). The amino-terminal DNA-binding region shared by DSX ${ }^{M}$ and $D S X^{F}$ (oval) is bound either to the $x$ or $y$ region. The carboxy-terminal regions are represented by a circle $\left(D_{S X}\right)$ and a square $\left(D S X^{M}\right)$. The equilibrium between alternative interactions is represented by paired horizontal arrows with

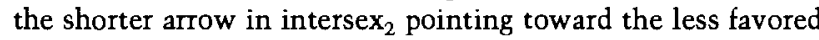
interaction. The third column lists the approximate FBE-directed promoter activities from Figs. 7 and 8. act from both $\mathrm{x}$ and $\mathrm{y}$ to influence the activators, we represent their influences as an equilibrium between effects from $x$ and $y$.

In summary, we have described results that establish a direct molecular link between arguably the best understood developmental regulatory pathway in higher organisms and certainly the best characterized target gene regulated by this pathway. Moreover, details of our results demonstrate that both a male and female protein from the pathway regulate the female specificity of the target gene: one repressing the gene in males and the other activating it in females. Finally, a model based on these results suggests how molecular signals from two different regulatory systems, namely the sex- and the tissue-specifying systems, may be integrated within the FBE enhancer.

\section{Materials and methods}

\section{DNA constructions}

The plasmid modpUC/FBE, used for mutagenesis of the three dsx-binding sites, contained FBE [ -322 to - 196 (Shepherd et al. 1985; Garabedian et al. 1986); all nucleotide positions are relative to the transcriptional start site of $Y p 1$ (Hung and Wensink 1981; Hovemann and Galler 1982)l, with $\mathrm{XbaI}$ and SaII restriction sites on both sides. This plasmid was made by transferring the BcII-EcoO109I fragment of Yp1 $\mid-322$ to -202$)$ into the $B c 7 I-E$ COO109I sites of a modified version of pUC19, called modpUC19 (the original EcoOl09I site of pUC19 was destroyed, and the polylinker was modified by insertion of a complementary pair of oligonucleotides into the $\mathrm{XbaI}$ site, adding the sequence CTAGAGTCGACTGATCAGATCTTCGTAGGCCCCGTCTCGAGT).

Binding site mutations were made by substitutions that maintained the normal spacing within FBE. Site A $\mid-307$ to -289 ) was modified by replacing the BclI-NlaIV fragment of FBE with a pair of complementary oligonucleotides, changing ACTACAATGTTGCAATC $(-304$ to -288$)$ to TGATATCCCACCGTTCG (Fig. 1; sub x). Site B (-283 to -254 ) was modified by replacing the NIaIV-MseI fragment of FBE with a pair of complementary oligonucleotides, changing AGTGATTACAAA $(-273$ to -262$)$ to TCACTAGTGTTT (Fig. 1; sub y). Site C $(-239$ to -222$)$ and downstream DNA $(-221$ to -196$)$ were changed using a polymerase chain reaction (PCR) technique (Saiki et al. 1988), exactly replacing GGTGCTGCTAAGTCATCAGTGGGGTCAGCTATAGGTAGGCCCCG $(-239$ to -196$)$ with CAGAGATCCTCTAGACTCGAGACGGGGCCTACGAAGATCTGATC (Fig. 1; sub $z$ ). Double and triple substitutions were created by combining the single-site mutations using similar techniques. Standard molecular cloning techniques were performed essentially as described by Schleif and Wensink (1981) or Maniatis et al. (1982). The sequence of each mutagenized structure was verified by sequencing (Tabor and Richardson 1987) using the Sequenase version 2.0 DNA Sequencing Kit (U.S. Biochemical).

The reporter gene vector used for germ-line transformations, $-44 \mathrm{hsp} / \mathrm{lac}$, is a modified version of the construct used previously, - $196 \mathrm{hsp} / \mathrm{lac}$ (Shepherd et al. 1985; Garabedian et al. 1986). The new construct deletes hsp70 DNA between -194 and -44 by a multistep procedure. The $X$ hol site of pSPl.1-194 (Costlow et al. 1985) was changed to $X b a I$, and the resulting $X b a I$ fragment containing the $h s p 70-1 a c Z$ gene fusion (a fusion between codon 337 of $h s p 70$ and codon 8 of $l a c Z$; Lis et al. 1983) 
was then inserted into the $X b a I$ site of CP20.1. The XbaI site at the $3^{\prime}$ end of the $l a c Z$ gene was destroyed by partial restriction, fill-in, and religation. This plasmid, pSXhLac7, was constructed and generously provided by Claude Maina Brandeis University). The heat shock elements were removed from pSXhLac 7 by changing the XhoI site of pSP1.1-43 (Costlow et al. 1985) to XbaI and then swapping the resulting $X b a I-M s t I$ fragment containing the promoter with the homologous fragment in pSXhLac7, creating $-44 \mathrm{hsp} / \mathrm{lac}$.

FBE and the mutated FBEs were excised from plasmid mod$\mathrm{pUC} / \mathrm{FBE}$ and its derivatives by $\mathrm{XbaI}$ or Sall digestion and then inserted into the unique $X b a I$ or $S a l I$ sites that lie between the $3^{\prime}$ end of the rosy (ry) gene and the hsp70 promoter (Fig. 4). All versions of FBE were placed at exactly the same distance from the $h s p 70$ promoter. The sequence and position of each insertion was verified by sequencing.

\section{DNase I footprinting}

The DNA fragments used in DNase I footprinting assays were made by PCR, essentially as described by Higuchi et al. (1988) using oligonucleotide primers complementary to flanking polylinker regions. DNase I footprinting assays (Galas and Schmitz 1978) were performed as described previously (Burtis et al. 1991) using 4 fmoles $(0.5 \mathrm{ng} ; 77,000 \mathrm{cpm})$ of labeled fragment, $40 \mathrm{ng}$ of poly $[\mathrm{d}(\mathrm{I}-\mathrm{C})] /[\mathrm{d}(\mathrm{I}-\mathrm{C})]$ and varying amounts of extract from $E$. coli overproducing DSX ${ }^{\mathrm{M}}, \mathrm{DSX}^{\mathrm{F}}$, or the expression vector with no $d s x$ insert. The expression constructs used in these experiments encode full-length dsx proteins with no additional amino acids. The control expression vector and constructs expressing DSX ${ }^{M}$ were generously provided by K. Burtis (University of California, Davis); the construct encoding DSX ${ }^{F}$ was generously provided by S. Cho (Brandeis University).

\section{Germ-line transformation}

P-element-mediated germ-line transformation was performed according to the method of Spradling and Rubin (1982). Embryos from a $\mathrm{ry}^{-}$strain of Drosophila ( $r y^{506}$ ) were injected with the $\mathrm{FBE} / \mathrm{hsp} / \mathrm{lac}$ plasmids at $350 \mu \mathrm{g} / \mathrm{ml}$ and $\mathrm{p} \pi 25.7 \mathrm{wc}$ (Karess and Rubin 1984) at $150 \mu \mathrm{g} / \mathrm{ml}$. Transformants were made homozygous using either $\mathrm{CyO} / \mathrm{Sco}$; ry/ry or TM2,Ubx,ry/MKRS,Sb,ry balancer strains. Because many of the lines were either homozygous lethal or sterile, additional transformant lines were created using the "jump starter" method of Robertson et al. (1988). The number of reporter gene inserts was determined by the method of Southern (1975). A minimum of three homozygous viable, single insert lines were obtained for each construct.

\section{dsx mutant flies}

$d s x$ is located on the third chromosome; $B^{\mathrm{S}}$, the marker used to distinguish $\mathrm{XX}$ and $\mathrm{XY}$ flies, is on the $\mathrm{Y}$ chromosome. Transformants with $\mathrm{FBE} / \mathrm{hsp} / \mathrm{lac}$ inserts on the second chromosome were selected for these experiments. Each FBE/hsp/lac fusion was crossed into each $d s x$ background ( $d s x$ strains obtained from R. Nagoshi, University of Iowa, Iowa Cityl, and the appropriate $d s x$ alleles (combined with the fusions) were crossed to generate the desired progeny.

The parental $d s x$ strains used for crosses to produce flies deficient in $\mathrm{dsx}$ proteins were $B^{S} \mathrm{Y} /+;+/+; d s x^{M+R 15} /$ TM $6 \mathrm{~b}(T b, H u, e)$ and $B^{S} \mathrm{Y} /+;+/+; \operatorname{In}(3 \mathrm{R}) d s x^{D+R 3} e / \mathrm{TM} 6 \mathrm{~b}$ (Tb,Hu,e) (Duncan and Kaufman 1975; Baker et al. 1991). The genotypes of the assayed flies were: $B^{S} \mathrm{Y} /+_{;}{ }^{*}{ }^{*} ; d s x^{M+R 15} /$ TM2 (Ubx,ry) for the $\mathrm{X} / \mathrm{Y}$ males and $B^{S} \mathrm{Y} /+;{ }^{*}{ }^{*} ; d s x^{M+R 15}$, $\operatorname{In}(3 \mathrm{R}) d s \mathrm{x}^{D+R 3} e$ for the $\mathrm{X} / \mathrm{Y}$ intersexes and $+/+; * /{ }^{*}$; $d s x^{M+R 15} / \mathrm{In}(3 \mathrm{R}) d s x^{D+R 3} e$ for the $\mathrm{X} / \mathrm{X}$ intersexes and $+1+$; ${ }^{*} /{ }^{\star} ; d s x^{M+R 15} / \mathrm{TM} 2(U b x, r y)$ for the $\mathrm{X} / \mathrm{X}$ females. In these genotypes, the asterisk indicates the $\mathrm{FBE} / \mathrm{hsp} /$ lac insertions on the second chromosome.

The parental $d s x$ strains used for crosses to introduce the $d s x$ dominant mutation, $d s x^{\mathrm{T}}$ (Nagoshi and Baker 1990), synthesizing DSX ${ }^{M}$ in both males and females, were $B^{S} \mathrm{Y} /+;+1+; d s X^{T} /$ $\mathrm{TM} 3\langle S b)$ and $B^{S} \mathrm{Y} /+;+1+; d s x^{M+R 15} / \mathrm{TM} 6 \mathrm{~b}(\mathrm{~T} b, H u, e)$. The genotypes of the assayed flies were: $B^{S} \mathrm{Y} /+;{ }^{*} /{ }^{*} ; d s \mathrm{X}^{T} /$ $d s x^{M+R 15}$ for $\mathrm{X} / \mathrm{Y}$ males and $+/+^{*}{ }^{*}{ }^{\star} ; d s \mathrm{X}^{T} / d s X^{M+R 15}$ for $\mathrm{X} / \mathrm{X}$ pseudomales and $+/+^{*}{ }^{*} ; d s \mathrm{X}^{\mathrm{T}} / \mathrm{TM} 2(U b \mathrm{C}, \mathrm{ry})$ for $\mathrm{X} / \mathrm{X}$ intersexes and $+1+;{ }^{*} /{ }^{*}$; MKRS $(S b, r y \mid / T M 2(U b x, r y)$ for $\mathrm{X} / \mathrm{X}$ females.

\section{Histochemical and spectrophotometric assays of $\beta$-galactosidase activity}

The X-gal (5-bromo-4-chloro-3-indolyl- $\beta$-galactopyranoside) histochemical staining assay of $\beta$-galactosidase activity has been described (Lis et al. 1983). Flies, 0-2 days old (grown at $25^{\circ} \mathrm{C}$ ) were aged for 3 days on food supplemented with live yeast paste. After aging, flies were anesthetized with $\mathrm{CO}_{2}$, rinsed in a solution of Ringer's buffer containing $0.1 \%$ Triton X-100, dissected in X-gal staining buffer, and stained overnight. Aging reduced the level of larval fat body cells in adults (Butterworth 1972) and allowed maximal expression of the reporter in adult fat body cells. To account for effects of chromosomal location on activity, a minimum of five independently transformed lines were examined for each construct.

CPRG spectrophotometric assays of $\beta$-galactosidase activity were performed essentially as described by Simon and Lis (1987). At least three homozygous viable, single insert lines were assayed for each construct. Five males, five pseudomales, four intersexes, or three females, aged 2, 3, or 4 days as described above, were homogenized in $250 \mu \mathrm{l}$ of assay buffer $150 \mathrm{mM}$ potassium phosphate at $\mathrm{pH} 7.5,1 \mathrm{mM} \mathrm{MgCl}, 1 \mathrm{mM}$ PMSF) in a 1.5-ml Eppendorf tube and spun $15 \mathrm{~min}$ in a microcentrifuge at $4^{\circ} \mathrm{C}$. The supernatant was transferred to a new Eppendorf tube. Extract $130 \mu \mathrm{l}$ for high activity lines; $200 \mu \mathrm{l}$ for low activity lines) and additional buffer, a total of $200 \mu \mathrm{l}$, were added to 300 $\mu \mathrm{l}$ of assay buffer with $1 \mathrm{mg} / \mathrm{ml}$ of CPRG in a disposable cuvette, mixed, and incubated at room temperature. $A_{574}$ was recorded for $1 \mathrm{hr}$ at 15 -min intervals. Activity was calculated by dividing the slope by the number of whole-fly equivalents assayed (change in $A_{574} / \mathrm{min}$ per fly). After the aging step described above, flies could be collected on ice, frozen in liquid nitrogen, and stored at $-70^{\circ} \mathrm{C}$ for several weeks with no significant change in activity. The age of the fly (2-6 days) made no significant difference in assay results.

All lines for a given experiment were assayed on several different days. To correct for assay variations such as temperature, activity values were normalized to results with the four sub xy lines using the following equation: $N_{n}=\left(Z / W_{n}\right)^{\star} X_{n}$, where $n$ is the experiment number, $N$ is the normalized value, $X$ is the experimental value, $W$ is the average of the $X$ values for the four sub xy lines assayed in experiment $n$, and $Z$ is the average of all $W$ values.

\section{Acknowledgments}

We thank Lark Claassen, Marie Lossky, Ranjan Sen, Chris Boles, and Wenqian An for critical comments on the manuscript, Mariana Wolfner and Ken Burtis for helpful discussions, and the National Institutes of Health for support of this research (GM21626 and GM46237). We gratefully acknowledge the gifts 
of plasmids and strains by Ken Burtis, Sayeon Cho, Rod Nagoshi, and Claude Maina.

The publication costs of this article were defrayed in part by payment of page charges. This article must therefore be hereby marked "advertisement" in accordance with 18 USC section 1734 solely to indicate this fact.

\section{References}

Abel, T., R. Bhatt, and T. Maniatis. 1992. A Drosophila CREB/ ATF transcriptional activator binds to both fat body and liver-specific regulatory elements. Genes \& Dev. 6: 466480.

Baker, B.S. 1989. Sex in flies: The splice of life. Nature 340: 521-524.

Baker, B.S. and K.A. Ridge. 1980. Sex and the single cell. I. On the action of major loci affecting sex determination in Drosophila melanogaster. Genetics 94: 383-423.

Baker, B.S., G. Hoff, T.C. Kaufman, M.F. Wolfner, and T. Hazelrigg. 1991. The doublesex locus of Drosophila melanogaster and its flanking regions: A cytogenetic analysis. Genetics 127: 125-138.

Bell, L.R., E.M. Maine, P. Schedl, and T.W. Cline. 1988. Sexlethal, a Drosophila sex determination switch gene exhibits sex-specific RNA splicing and sequence similarity to RNA binding proteins. Cell 55: 1037-1046.

Belote, J.M., A.M. Handler, M.F. Wolfner, K.J. Livak, and B.S. Baker. 1985. Sex-specific regulation of yolk protein gene expression in Drosophila. Cell 40: 339-348.

Boggs, R.T., P. Gregor, S. Idriss, J.M. Belote, and M. McKeown. 1987. Regulation of sexual differentiation in D. melanogaster via altemative splicing of RNA from the transformer gene. Cell 50: 739-747.

Bownes, M. and R. Nöthiger. 1981. Sex determining genes and vitellogenin synthesis in Drosophila melanogaster. Mol. \& Gen. Genet. 182: 222-228.

Bridges, C.B. 1921. Triploid intersexes in Drosophila melanogaster. Science 54: 252-254.

. 1925. Sex in relation to chromosomes and genes. Am. Nat. 59: 127-137.

Burtis, K.C. and B.S. Baker. 1989. Drosophila doublesex gene controls somatic sexual differentiation by producing alternatively spliced mRNAs encoding related sex-specific polypeptides. Cell 56: 997-1010.

Burtis, K.C., K.T. Coschigano, B.S. Baker, and P.C. Wensink. 1991. The doublesex proteins of Drosophila melanogaster bind directly to a sex-specific yolk protein gene enhancer. EMBO I. 10: 2577-2582.

Butterworth, F.M. 1972. Adipose tissue of Drosophila melanogaster. V. Genetic and experimental studies of an extrinsic influence on the rate of cell death in the larval fat body. Dev. Biol. 28: 311-325.

Chapman, K.B. and M.F Wolfner. 1988. Determination of malespecific gene expression in Drosophila accessory glands. Dev. Biol. 126: 195-202.

Cline, T.W. 1986. A female-specific lethal lesion in an X-linked positive regulator of the Drosophila sex determination gene, Sex-lethal. Genetics 113: 641-663.

. 1988. Evidence that sisterless- $a$ and sisterless $-b$ are two of several discrete "numerator elements" of the X/A sex determination signal in Drosophila that switch $S x l$ between two altemative stable expression states. Genetics 119: 829862.

Costlow, N.A., J.A. Simon, and J.T. Lis. 1985. A hypersensitive site in $H s p 70$ chromatin requires adjacent not internal DNA sequence. Nature 313: 147-149.

Duffy, J.B. and J.P. Gergen. 1991. The Drosophila segmentation gene runt acts as a position-specific numerator element necessary for the uniform expression of the sex-determining gene Sex-lethal. Genes \& Dev. 5: 2176-2187.

Duncan, I.W. and T.C. Kaufman. 1975. Cytogenetic analysis of chromosome 3 in Drosophila melanogaster: Mapping of the proximal portions of the right arm. Genetics 80: 733-752.

Erickson, J.W. and T.W. Cline. 1991. Molecular nature of the Drosophila sex determination signal and its link to neurogenesis. Science 251: 1071-1074.

Falb, D. and T. Maniatis, 1992. A conserved regulatory unit implicated in tissue-specific gene expression in Drosophila and man. Genes \& Dev. 6: 454-465.

Feng, Y., N.M. Schiff, and D.R. Cavener. 1991. Organ-specific patterns of gene expression in the reproductive tract of Drosophila are regulated by the sex-determination genes. Dev. Biol. 146: 451-460.

Galas, C. and A. Schmitz. 1978. DNAase footprinting: A simple method for the detection of protein-DNA binding specificity. Nucleic Acids Res. 5: 3157-3170.

Garabedian, M.J., B.M. Shepherd, and P.C. Wensink. 1986. A tissue-specific transcription enhancer from the Drosophila yolk protein 1 gene. Cell 45: 859-867.

Higuchi, R., B. Knummel, and R.K. Saiki. 1988. A general method of in vitro preparation and specific mutagenesis of DNA fragments: Study of protein and DNA interactions. Nucleic Acids Res. 16: 7351-7367.

Hovemann, B. and R. Galler. 1982. Vitellogenin in Drosophila melanogaster: A comparison of the YPI and YPII genes and their transcription products. Nucleic Acids Res. 10: 22612274.

Hung, M.C. and P.C. Wensink. 1981. The sequence of the Drosophila melanogaster gene for yolk protein 1. Nucleic Acids Res. 9: 6407-6419.

Johnson, M.B. and F.M. Butterworth. 1985. Maturation and aging of adult fat body and oenocytes in Drosophila as revealed by light microscopic morphometry. I. Morphol. 184: 51-59.

Karess, R.E. and G.M. Rubin. 1984. Analysis of P transposable element functions in Drosophila. Cell 38: 135-146.

Keyes, L.N., T.W. Cline, and P. Schedl. 1992. The primary sex determination signal of Drosophila acts at the level of transcription. Cell 68: 933-943.

Lis, J.T., I.A. Simon, and C.A. Sutton. 1983. New heat shock puffs and $\beta$-galactosidase activity resulting from transformation of Drosophila with an hsp70-lacZ hybrid gene. Cell 35: 403-410.

Maniatis, T., E.F. Fritsch, and J. Sambrook. 1982. Molecular cloning: A laboratory manual. Cold Spring Harbor Laboratory, Cold Spring Harbor, New York.

Maxam, A.M. and W. Gilbert. 1980. Sequencing end-labeled DNA with base-specific chemical cleavages. Methods Enzymol. 65: 499-560.

Nagoshi, R.N. and B.S. Baker. 1990. Regulation of sex-specific RNA splicing at the Drosophila doublesex gene: Cis-acting mutations in exon sequences alter sex-specific RNA splicing patterns. Genes \& Dev. 4: 89-97.

Nagoshi, R.N., M. McKeown, K.C. Burtis, J.M. Belote, and B.S. Baker. 1988. The control of alternative splicing at genes regulating sexual differentiation in D. melanogaster. Cell 53: $229-236$.

Ota, T., A. Fukunaga, M. Kawabe, and K. Oishi. 1981. Interactions between sex-transformation mutants of Drosophila melanogaster. I. Hemolymph vitellogenins and gonad morphology. Genetics 99: 429-441. 
Parkhurst, S.M., D. Bopp, and D. Ish-Horowitz. 1990. X : A ratio, the primary sex-determining signal in Drosophila, is transduced by helix-loop-helix proteins. Cell 63: 1179-1191.

Postlethwait, I., M. Bownes, and T. Jowett. 1980. Sexual phenotype and vitellogenin synthesis in Drosophila melanogaster. Dev. Biol. 79: 379-387.

Robertson, H.M., C.R. Preston, R.W. Phillis, D.M. JohnsonSchlitz, W.K. Benz, and W.R. Engels. 1988. A stable genomic source of $P$ element transposase in Drosophila melanogaster. Genetics 118: 461-470.

Saiki, R.K., D.H. Gelfand, S. Stoffel, S.J. Scharf, R. Higuchi, G.T. Horn, K.B. Mullis, and H.A. Erlich. 1988. Primer-directed enzymatic amplification of DNA with a thermostable DNA polymerase. Science 239: 487-491.

Salz, H.K., E.M. Maine, L.N. Keyes, M.E. Samuels, T.W. Cline, and P. Schedl. 1989. The Drosophila female-specific sex-determination gene, Sex-lethal, has stage-, tissue-, and sex-specific RNAs suggesting multiple modes of regulation. Genes \& Dev. 3: 708-719.

Schleif, R.F. and P.C. Wensink. 1981. Practical methods in molecular biology. Springer-Verlag, New York.

Shepherd, B., M.J. Garabedian, M.-C. Hung, and P.C. Wensink. 1985. Developmental control of Drosophila yolk protein 1 gene by cis-acting DNA elements. Cold Spring Harbor Symp. Quant. Biol. 50: 521-526.

Simon, J.A. and J.T. Lis. 1987. A germline transformation analysis reveals flexibility in the organization of heat shock consensus elements. Nucleic Acids Res. 15: 2971-2988.

Slee, R. and M. Bownes. 1990. Sex determination in Drosophila melanogaster. Q. Rev. Biol. 65: 175-204.

Sosnowski, B.A., J.M. Belote, and M. McKeown. 1989. Sex-specific alternative splicing of RNA from the transformer gene results from sequence-dependent splice site blockage. Cell 58: $449-459$.

Southern, E.M. 1975. Detection of specific sequences among DNA fragments separated by gel electrophoresis. $I$. Mol. Biol. 98: 503-517.

Spradling, A.C. and G.M. Rubin. 1982. Transposition of cloned P elements into Drosophila germline chromosomes. Science 218: 341-347.

Steinmann-Zwicky, M., H. Amrein, and R. Nöthiger. 1990. Genetic control of sex determination in Drosophila. $A d v$. Genet. 27: 189-237.

Tabor, S. and C.C. Richardson. 1987. DNA sequence analysis with a modified bacteriophage T7 DNA polymerase. Proc. Natl. Acad. Sci. 84: 4767-4771.

Taylor, B.J. and J.W. Truman. 1992. Commitment of abdominal neuroblasts in Drosophila to a male or female fate is dependent on genes of the sex-determining hierarchy. Development 114: 625-642.

Wolfner, M.F. 1988. Sex-specific gene expression in somatic tissues of Drosophila melanogaster. Trends Genet. 4: 333-337. 


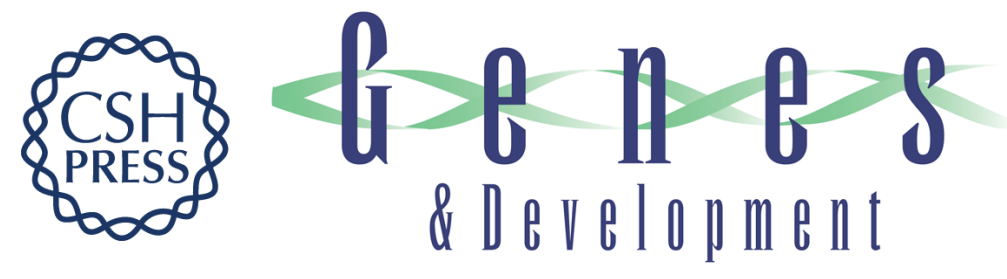

\section{Sex-specific transcriptional regulation by the male and female doublesex proteins of Drosophila.}

K T Coschigano and P C Wensink

Genes Dev. 1993, 7:

Access the most recent version at doi:10.1101/gad.7.1.42

References This article cites 50 articles, 19 of which can be accessed free at:

http://genesdev.cshlp.org/content/7/1/42.full.html\#ref-list-1

License

Email Alerting

Service

Receive free email alerts when new articles cite this article - sign up in the box at the top right corner of the article or click here.

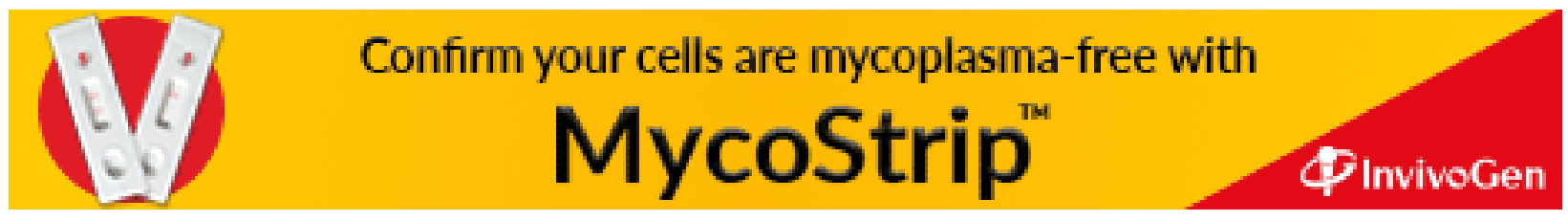

